\title{
Molecular detection of tick-borne pathogens in captive wild felids, Zimbabwe
}

\author{
Patrick Kelly ${ }^{1}$, Lisa Marabini ${ }^{2}$, Keith Dutlow ${ }^{2}$, Jilei Zhang ${ }^{3}$, Amanda Loftis ${ }^{4}$ and Chengming Wang ${ }^{3^{*}}$
}

\begin{abstract}
Background: The populations of wild felids in Africa, of especially lions (Panthera leo) and cheetahs (Acinonyx jubatus), are declining and the species are classified as vulnerable to extinction by the International Union for Conservation of Nature. As infections with tick-borne pathogens (TBP) can become more of a problem in wild felids, there are relatively few studies on TBP in wild felids in Africa and on how these infections might influence population numbers.

Methods: To gain further knowledge on TBP in captive wild felids in Southern Africa, we collected whole blood from captive lions, Southern African wildcats, cheetahs and servals in Zimbabwe for PCRs against the 18S rRNA gene of the piroplasmids (Babesia, Theileria, Cytauxzoon) and Hepatozoon spp., and the 16S rRNA gene of Ehrlichia and Anaplasma spp.
\end{abstract}

Results: Overall, $78 \%$ of the lions (67/86) and all the Southern African wildcats (6/6), cheetahs (4/4) and servals (2/2) had evidence of infection with at least one organism. The organisms most commonly detected in the lions were $B$. leo (59\%; 51/86), B. vogeli (12\%; 10/86) and H. felis (11\%; 9/86) while all the Southern African wildcats and servals were positive for B. vogeli and all the cheetahs were positive for B. leo. Mixed infections were found in 22\% (15/67) of the PCR positive lions, most commonly B. leo and H. felis (27\%; 4/15), and in 1 (50\%) of the servals (B. vogeli and A. phagocytophilum). Two lions were infected with three TBP, mainly B. leo, H. canis and T. parva, and B. leo, A. phagocytophilum and $T$. sinensis. Mixed infections with $B$. vogeli and $A$. phagocytophilum were seen in a serval and a Southern African wildcat. Other TBP were detected at a low prevalence $(\leq 2 \%)$ in lions, mainly $H$. canis, $T$. sinensis, $T$. parva, C. manul, E. canis, and E. canis-like and B. odocoilei-like organisms.

Conclusions: Infections with tick-borne agents are common in captive wild felids in Zimbabwe.

Keywords: Babesia, Ehrlichia, Anaplasma, Wild felids, Zimbabwe

\section{Background}

The populations of wild felids in Africa, especially lions (Panthera leo) and cheetahs (Acinonyx jubatus), are declining and the species are classified as vulnerable to extinction by the International Union for Conservation of Nature (http://www.iucnredlist.org, accessed $21^{\text {st }}$ July 2014). Similarly, although figures are not available, the Southern African wildcat (Felis silvestris cafra) is thought to be endangered due to hybridization with domestic cats and contracting their infectious diseases [1]. Human expansion has resulted in loss of natural habitat for the

\footnotetext{
* Correspondence: wangcm@yzu.edu.cn

${ }^{3}$ Jiangsu Co-innovation Center for Prevention and Control of Important Animal Infectious Diseases and Zoonoses, Yangzhou University College of Animal Science and Technology, Yangzhou, Jiangsu 225009, China Full list of author information is available at the end of the article
}

endangered wild felids which are increasingly being incorporated into wildlife reserves or parks where they play an important role in ecotourism, a major source of revenue for many African countries. In these smaller territories, ectoparasites can become more of a problem and this may increase the possibility of infections with tick-borne agents [2].

There are relatively few studies on TBP in wild felids in Africa and thus little information on how these infections might influence population numbers. The earlier studies in which parasites were identified microscopically $[3,4]$ are of limited value, as many TBP are difficult to detect in blood films and it is not generally possible to determine the species of pathogens by morphological criteria. More recent studies using molecular methods 
have provided greater details on the agents that infect lions and cheetahs but only five have been carried out to date describing the situation in 436 lions and 142 cheetah in seven countries: 81 lions from South Africa and Swaziland and 137 cheetah from South Africa and Namibia [5], 21 lions in Botswana [6], 301 lions in Tanzania [7], 9 lions and 5 cheetah in Kenya [8] and 24 lions in Zambia [9]. To add to this current knowledge, we studied TBP in lions, Southern African wildcats, cheetahs and serval (Leptailurus serval) from Zimbabwe and describe our findings below.

\section{Methods}

\section{Whole blood samples}

Whole blood samples $(n=98)$ were collected into EDTA from apparently healthy captive lions in the towns of Gweru $(n=67)$ and Masvingo $(n=6)$ and Dollar Block farm $(n=8)$. They were also collected from captive Southern African wildcats $(n=6)$, cheetahs $(n=4)$ and servals $(n=2)$ in the city of Harare. Five further lions were sampled in the town of Gweru, within days of being translocated from the town of Hwange $(n=3)$ and the village of Fig tree $(n=2)$ where they had been kept in captivity. All animals in the study were over 6 months of age and all had been in captivity for at least 6 months. They were apparently healthy and were sampled while being anesthetized for microchipping and routine health monitoring or procedures. The study was reviewed and approved by the Institutional Animal Care and Use Committee of the Ross University School of Veterinary Medicine (RUSVM), St Kitts.

\section{DNA extraction and quality control}

After collection, blood samples were frozen in Zimbabwe at $-20^{\circ} \mathrm{C}$ before being sent on ice to RUSVM where DNA was extracted from aliquots $(200 \mu \mathrm{l})$ using the QIAamp DNA Blood Mini Kit (Qiagen, Valencia, CA, USA) according to the manufacturer's instructions. The DNA was eluted in $200 \mu \mathrm{l}$ elution buffer and shipped to Yangzhou University College of Veterinary Medicine of China at room temperature where it was frozen at $-80^{\circ} \mathrm{C}$ until PCRs were performed.

\section{PCRs}

The PCRs were performed on a Roche LightCycler 480II platform. The HMBS gene was used as an endogenous control [10] and a conventional PCR was used to detect a 848-bp fragment of the $18 \mathrm{~S}$ rRNA gene with previously described primers (BTF1 - forward: 5'-GGCTCATTACAACAGTTATAG-3'; BTR2 - reverse: 5'-GGACTACGACGGTATCTGATCG-3') [11]. These primers are reported to detect most species of Babesia and Theileria. To ensure the primers detected the feline Babesia spp., we used them in the BLASTN program to search the sequence data available on GenBank.
A conventional PCR was also performed to detect a 478 base pair fragment of the 16S rRNA gene of Ehrlichia spp. and Anaplasma spp. using primers (ECC - forward: 5'AGAACGAACGCTGGCGGCAAGCC-3'; ECB - reverse: 5'-CGTATTACCGCGGCTGCTGGCA-3') described previously [12].

Positive and negative controls were as described in the relevant references. For all PCRs, positive products were verified by gel electrophoresis and nucleotide sequencing using forward and antisense primers (GenScript, Nanjing, China).

\section{Results}

The HMBS-based FRET-PCR showed average HMBS copy numbers in the 97 samples to be $3.5 \pm 1.2 \times 10^{6}$ copies/ml whole blood (range $4.0 \times 10^{4}$ to $2.5 \times 10^{7}$ ), indicating the DNA in each sample was of sufficient quality for further PCR studies. The BLASTN program showed the BTF1 and BTR2 primers had 100\% identity with the 18S rRNA gene of three genera (Babesia spp., Theileria spp., and Hepatozoon spp.) and only a single base pair mismatch in the BTF1 with Cytauxzoon spp. The primers recognized all the feline Babesia spp. with $100 \%$ identity, except for B. felis where there was a single mismatch in the BTF1.

Following generally accepted rules of taxonomy [13], organisms we identified with sequences that were at least 97\% identical to a recognized TBP on GenBank were regarded to be that species while those with lesser identity were regarded to be species-like. Sequences with under $100 \%$ identity and at least 200 base pairs in length were submitted to GenBank and the following accession numbers were obtained: KJ598879 - 94\% identity with E. canis, KJ598888 - 97.6\% identity with E. canis, KJ598889 - 99.4\% identity with A. phagocytophilum; KJ598890 - 99.5\% identity with A. phagocytophilum; KJ598891 - 99.3\% identity with A. phagocytophilum, KJ598880 - 97.5\% identity with B. vogeli; KJ598881 - 94.8\% identity with B. odocoilei; KJ598882 - 94.6\% identity with B. odocoilei; KJ598886 99.3\% identity with H. felis; KJ598887 - 99.2\% identity with H. felis; KM211712 - 99.5\% identity with T. parva.

Overall, very high percentages of lions $(78 \% ; 67 / 86)$, Southern African wildcats (100\%; 6/6), cheetahs $(100 \% ; 4 / 4)$ and servals $(100 \% ; 2 / 2)$ had evidence of infection with at least one of the TBP (Table 1). Each of the nine recognized TBP we found, as well as B. odocoilei-like and E. canis-like organisms, were present in the lions while only $B$. vogeli and A. phagocytophilum were found in Southern African wildcats and servals, and only B. leo in cheetahs. Overall, the most common TBP we detected in the animals we studied was B. leo $(56 \% ; 55 / 98)$ with B. vogeli $(18 \% ; 18 / 98)$ being the next most prevalent. Infections with a single organism were seen in 78\% (52/67) of the PCR positive lions, mainly B. leo (38), B. vogeli (9), B. odocoilei-like (1), H. felis 
Table 1 Survey sites, animals tested and results of PCR analyses for tick borne pathogens

\begin{tabular}{|c|c|c|c|c|c|c|c|c|c|c|c|}
\hline Species & Area & $\mathrm{N}$ & $\begin{array}{l}\text { Babesia } \\
\text { leo }\end{array}$ & $\begin{array}{l}\text { Babesia } \\
\text { vogeli }\end{array}$ & $\begin{array}{l}\text { Hepatozoon } \\
\text { felis }\end{array}$ & $\begin{array}{l}\text { Hepatozoon } \\
\text { canis }\end{array}$ & $\begin{array}{l}\text { Anaplasma } \\
\text { phagocytophilum }\end{array}$ & $\begin{array}{l}\text { Theileria } \\
\text { sinensis }\end{array}$ & $\begin{array}{l}\text { Theileria } \\
\text { parva }\end{array}$ & $\begin{array}{l}\text { Cytauxzoon } \\
\text { manul }\end{array}$ & $\begin{array}{l}\text { Ehrlichia } \\
\text { canis }\end{array}$ \\
\hline \multirow[t]{6}{*}{ Lions } & Gweru* & 67 & $64 \%(43)$ & $12 \%(8)$ & $11 \%(7)$ & $3 \%(2)$ & $8 \%(5)$ & $2 \%(1)$ & $2 \%(1)$ & $2 \%(1)$ & \\
\hline & $\begin{array}{l}\text { Dollar } \\
\text { Block }\end{array}$ & 8 & $63 \%(5)$ & & & & & & & & $12 \%(1)$ \\
\hline & Hwange & 3 & $33 \%(1)$ & $67 \%(2)$ & & & $33 \%(1)$ & & & & \\
\hline & Fig Tree & 2 & $50 \%(1)$ & & $100 \%(2)$ & & & & & & \\
\hline & Masvingo & 6 & $17 \%(1)$ & & & & & & & $17 \%(1)$ & \\
\hline & All lions & 86 & $59 \%(51)$ & $12 \%(10)$ & $11 \%(9)$ & $2 \%(2)$ & $7 \%(6)$ & $1 \%(1)$ & $1 \%(1)$ & $2 \%(2)$ & $1 \%(1)$ \\
\hline $\begin{array}{l}\text { Southern } \\
\text { African } \\
\text { wildcats }\end{array}$ & Harare & 6 & & $100 \%(6)$ & & & $13 \%(1)$ & & & & \\
\hline Cheetahs & Harare & 4 & $100 \%(4)$ & & & & & & & & \\
\hline Servals & Harare & 2 & & $100 \%(2)$ & & & $50 \%(1)$ & & & & \\
\hline Totals & & 98 & $56 \%(55)$ & $18 \%(18)$ & $9 \%(9)$ & $2 \%(2)$ & $8 \%(8)$ & $1 \%(1)$ & $1 \%(1)$ & $2 \%(2)$ & $1 \%(1)$ \\
\hline
\end{tabular}

*Also present were 2 lions infected with B. odocoilei-like organisms and 1 with an E. canis-like organism.

(3), or C. manul (1). Mixed infections were seen in $22 \%$ of the PCR positive lions (15/67) [B. leo and H. canis (1); B. leo and E. canis (1); B. leo and E. canis-like (1); B. leo and H. felis (4); B. leo and A. phagocytophilum (3); B. leo, H. canis and T. parva (1); B. leo, A. phagocytophilum and T. sinensis (1); B. leo, A. phagocytophilum and $H$. felis (1); B. vogeli and $H$. felis (1); or B. odocoilei-like and C. manul (1)]. A mixed infection with B. vogeli and A. phagocytophilum was seen in one of the servals and one of the Southern African wildcats, but there were no mixed infections in the cheetahs (Table 1).

\section{Discussion}

The wild felid species we studied in Zimbabwe were commonly infected with Babesia with 73\% (63/86) of the lions and all the Southern African wildcats (6), cheetahs (4) and servals (2) being PCR positive. All animals were apparently healthy at the time of blood collection, indicating a high prevalence of chronic subclinical infections. The most common TBP we identified was B. leo which we identified in $59 \%$ of the lions and all the cheetahs (4) we studied. Babesia leo is a small Babesia spp. which was first described in 2001 [14] and has been reported to be very common in lions $(28 \%)$ in Southern Africa [5] but far less common in Tanzania $(<1 \%)$ [7]. It has only been previously reported at low prevalence $(0-$ $3 \%)$ in cheetahs in Southern Africa. Phylogenetic analysis shows it forms a group with B. felis which infects domestic cats, B. microti which infects rodents and humans, and $B$. rodhaini which infects rodents. The vector of $B$. leo is unknown, but infected lions have been found to be commonly infested with Amblyomma hebraeum, Haemaphysalis leachi and Rhipicephalus simus [14]. While we did not study the ectoparasites on the animals we tested, local experience is that captive lions are more commonly infested with ticks while cheetahs have light tick burdens but more severe flea infestations. Tick and flea control products used by owners of wild felids in Zimbabwe include Deltatick Pour On ${ }^{\circledR}$ (Chemplex, Harare, Zimbabwe), a topical 5\% deltamethrin product for use in cattle, and Frontline Spray ${ }^{\odot}$ (Merial, South Africa), a fipronil based product reported to control fleas and ticks on dogs. To the best of our knowledge these products have not been evaluated for efficacy or safety in wild felids.

Although around 1\% of stray domestic cats in Thailand have been found to be infected with $B$. vogeli [15] ours is the first report of the organism in Southern African wildcats $(100 \% ; 6 / 6)$, lions $(12 \% ; 10 / 86)$ and servals $(100 \% ; 2 / 2)$. Babesia vogeli commonly infects dogs in tropical and subtropical areas with prevalences of 4-60\% [16]. The organism is transmitted by $R$. sanguineus and infections are mostly asymptomatic with dogs becoming subclinical carriers [17]. Rhipicephalus sanguineus was not found on Southern African domestic or wild felids in a recent survey which was regarded as consistent with the near-strict host preference of the tick for domestic dogs [2]. Further studies are needed to determine the transmission mechanisms in wild felids.

We found no evidence of $B$. felis in the wild felids we studied which was also the case in a study of 2 lions and 5 cheetahs from Kenya [8]. Nevertheless, infections have been described in lions and cheetahs, both free-living and captive, from Southern Africa (4-28\%) [5] as well as in lions from Zambia (number not given) [9] and Tanzania (number not given) [7]. One infected serval has also been reported [18]. A possible reason we failed to detect the organism is because the BTF1 primer we used in our PCR had a mismatch with $B$. felis which might have reduced the sensitivity of the reaction and required relatively high copy numbers of $B$. felis to give positive reactions. Also, 
our detection system using a standard PCR and sequencing is not sensitive for mixed infections which are reported to be common using methods which are more accurate in their detection [5]. Investigations with more specific $B$. felis primers are planned to resolve this issue.

We also failed to identify the other Babesia spp. that have been described in wild felids in Africa. In Tanzania and Kenya, lions have been found to be infected with an organism most similar to B. gibsoni [7] and B. canis (98\% identity) [8], respectively, both of which have previously only been described in dogs. Babesia lengau is a recently described species that was found in a high percentage (29\%) of cheetahs in South Africa [19]. A closely related species has been found in spotted hyenas (Crocuta crocuta) and a lion in Zambia [9]. The organism appears to result in asymptomatic infections in cheetahs, but in domestic cats [20] and sheep [21], B. lengau and a closely related organism, have been reported to cause cerebral and hemolytic babesiosis, and hemolytic disease, respectively.

Undescribed Babesia spp. have been reported to be common in African wild felids [5] and we found an $B$. odocoilei-like organism in two lions. This large Babesia has, to date, only been described in North America in a variety of wild ruminants [22]. Recently seropositive rabbits have been reported [23] and the amplicons of PCRs for Babesia on two Florida panthers (Puma concolor coryi) had similar sequences [24]. Also, Ixodes ovatus from dogs in Japan have been found to contain B. odocoilei-like organisms (97.7\% identical) [25]. It is of note that a large Babesia has been described in a domestic cat from Zimbabwe [26] and further studies are indicated to more clearly describe these novel Babesia spp.

Although Cytauxzoon spp. have been described by molecular studies in wild felids from US [27], Spain [28] and Brazil [29], ours is the first report of the organism in wild felids in Africa. Sequencing of the organism showed it was most similar to C. manul (99\% identity) which is found in Pallas cats (Otocolobus manul) in Mongolia [30]. While a cytauxzoonosis-like disease has been described in a domestic cat in Zimbabwe [31], experimental infection studies using $C$. manul in domestic cats resulted in no clinical signs although there was a low parasitemia [32].

Our finding of Hepatozoon spp. in both lions and cheetahs was not unexpected as they have been seen frequently in blood smears from African wild felids [3,4]. There is little data, however, on their molecular biology with organisms being identified by molecular means in $38 \%$ of Zambian lions [9], an unspecified number in lions from Tanzania [7], and 55\% of Asiatic lions [33]. The species identified in the Asian and Tanzanian lions was $H$. felis while $H$. canis-like organism were detected in the Zambian lions. There is considerable diversity in Hepatozoon spp. in wild canids in the US [34] and further studies are indicated to determine if this is also the case in African wild felids. Although generally regarded as being nonpathogenic in wild felids, there is a report of Hepatozoon infection perhaps contributing to the death of spotted hyenas (Crocuta crocuta) in Tanzania. The organism involved had a $18 \mathrm{~S}$ RNA gene sequence identical to that of a Hepatozoon sp. described previously in domestic cats in Spain which is distinct from $H$. canis [35].

Although Theileria-like parasites have been seen in blood films of cheetahs from Tanzania [4] and South Africa [36] there has been only a single report of the molecular identification of organisms in African wild felids. With reverse line blots, Theileria spp. were found in cheetahs and a lion from Kenya with sequencing indicating the parasites were closely related to those infecting sheep and giraffes [8]. We had positive PCR reactions for two lions with sequencing showing the organisms were most similar to T. parva, the agent of Corridor disease and East Coast Fever in domestic ruminants, and $T$. sinensis that infects cattle and yaks in China [37]. Neither of these species has been described in felids and further genomic studies are required to more precisely characterize the organisms and determine their pathogenicity.

Six of the lions, one of the servals, and one of the Southern African wildcats we studied were infected with an organism most similar to $A$. phagocytophilum, a tickborne rickettsia infecting a wide range of species including domestic and wild ruminants, horses, dogs, humans and domestic cats. It has been found in wild felids outside of Africa, including up to $10 \%$ of lions in Italy and California [38,39], but none of 21 free ranging lions in Botswana were seropositive [6]. Although widely distributed in the Northern Hemisphere where it's Ixodes spp. vectors are common, in Sub-Saharan Africa A. phagocytophilum has only been described in three sheep in Senegal [40] and a closely related organism was reported in a dog in South Africa [41]. A. phagocytophilum can cause severe disease in animals and people and in domestic cats has been reported to cause fever, lethargy and inappetence with non-specific signs including tachypnea, muscle and joint pain, neurological signs and lymphadenomegaly that respond to tetracycline therapy [42-46].

Ehrlichia canis is the rickettsial agent of canine monocytic ehrlichiosis which is transmitted by the brown dog tick, Rhipicephalus sanguineus. Infected dogs are found very commonly around the world but infections in domestic cats are only reported infrequently. In many cases the cats are asymptomatic but signs including intermittent fever, weight loss, vomiting and diarrhea have been reported, as have thrombocytopenia and anemia [47]. Small numbers of wild felids infected with $E$. canis have been reported from Brazil $[48,49]$ and Japan [50] and, although a serosurvey in Botswana [6] and a PCR survey 
in Zambia [9] were negative, there is evidence of E. canis infections in domestic cats in Southern Africa [51]. Our finding of two lions infected with $E$. canis or E. canis-like organisms is consistent with the available data showing infections are uncommon in felids generally. This may be related to the fact that the vector of $E$. canis, the brown $\operatorname{dog}$ tick $R$. sanguineus, very seldom feeds on species other than the domestic dog [2].

\section{Conclusions}

In summary, our study has added to the knowledge of the tick-borne infections of wild felids in Southern Africa. Although further molecular studies are needed to more precisely determine the range of species involved, the available evidence is that infections with tick-borne agents are common, perhaps more particularly in captive animals where ticks can become more prevalent. Although most of the infected wild felids we tested appeared healthy and most likely had chronic infections, studies are needed to determine if there are signs associated with acute infections and if the tick-borne organisms can potentiate other conditions. Studies are also needed on optimal ways of controlling ticks in captive wild felids to control infections.

\section{Competing interests}

The authors declare that they have no competing interests.

\section{Authors' contributions}

$\mathrm{PK}, \mathrm{CW}$ and $\mathrm{AL}$ designed the study and wrote the manuscript. $L M, K D$, and $J Z$ collected the samples, performed the experiments and reviewed the manuscript. All authors participated in the revision of the manuscript, read, and approved the submitted version.

\section{Acknowledgments}

This project was supported by the Ross University School of Veterinary Medicine, the Animal and Wildlife Area Research and Rehabilitation (AWARE) Trust of Zimbabwe, the National Natural Science Foundation of China (NO: 31272575, 31472225), and the Priority Academic Program Development of Jiangsu Higher Education Institutions.

\section{Author details}

${ }^{1}$ Ross University School of Veterinary Medicine, Basseterre, St. Kitts and Nevis. ${ }^{2}$ AWARE Trust, Harare, Zimbabwe. ${ }^{3}$ Jiangsu Co-innovation Center for Prevention and Control of Important Animal Infectious Diseases and Zoonoses, Yangzhou University College of Animal Science and Technology, Yangzhou, Jiangsu 225009, China. ${ }^{4}$ Department of Microbiology \& Immunology, Midwestern University, Glendale, AZ, USA.

Received: 27 August 2014 Accepted: 1 November 2014

Published online: 18 November 2014

\section{References}

1. Driscoll CA, Menotti-Raymond M, Roca AL, Hupe K, Johnson WE, Geffen E, Harley EH, Delibes M, Pontier D, Kitchener AC, Yamaguchi N, O'brien SJ, Macdonald DW: The Near Eastern origin of cat domestication. Science 2007, 317:519-523.

2. Horak IG, Heyne H, Donkin EF: Parasites of domestic and wild animals in South Africa. XLVIII. Ticks (Acari: Ixodidae) infesting domestic cats and wild felids in Southern Africa. Onderstepoort J Vet Res 2010, 77:E1-E7.

3. McCully RM, Basson PA, Bigalke RD, De Vos V, Young E: Observations on naturally acquired hepatozoonosis of wild carnivores and dogs in the Republic of South Africa. Onderstepoort J Vet Res 1975, 42:117-133.
4. Averbeck GA, Bjork KE, Packer C, Herbst L: Prevalence of hematozoans in lions (Panthera leo) and cheetah (Acinonyx jubatus) in Serengeti National Park and Ngorongoro Crater, Tanzania. J Wildl Dis 1990, 26:392-394.

5. Bosman AM, Venter EH, Penzhorn BL: Occurrence of Babesia felis and Babesia leo in various wild felid species and domestic cats in Southern Africa, based on reverse line blot analysis. Vet Parasitol 2007, 144:33-38.

6. Ramsauer S, Bay G, Meli M, Hofmann-Lehmann R, Lutz H: Seroprevalence of selected infectious agents in a free-ranging, low-density lion population in the Central Kalahari Game Reserves in Botswana. Clin Vaccine Immunol 2007, 14:808-810.

7. Munson L, Terio KA, Kock R, Mlengeya T, Roelke ME, Dubovi E, Summers B, Sinclair AR, Packer C: Climate extremes promote fatal co-infections during canine distemper epidemics in African lions. PLoS One 2008, 3:e2545.

8. Githaka N, Konnai S, Kariuki E, Kanduma E, Murata S, Ohashi K: Molecular detection and characterization of potentially new Babesia and Theileria species/variants in wild felids from Kenya. Acta Trop 2012, 124:71-78.

9. Williams BM, Berentsen A, Shock BC, Teixiera M, Dunbar MR, Becker MS, Yabsley MJ: Prevalence and diversity of Babesia, Hepatozoon, Ehrlichia, and Bartonella in wild and domestic carnivores from Zambia, Africa. Parasitol Res 2014, 113:911-918.

10. Wei L, Kelly P, Zhang J, Yang Y, Zheng X, Tao J, Zhang Z, Wang C: Use of a universal hydroxymethylbilane synthase (HMBS)-based PCR as an endogenous internal control and to enable typing of mammalian DNAs. Appl Microbiol Biotechnol 2014, 98:5579-5587.

11. Jefferies $R$, Ryan UM, Irwin PJ: PCR-RFLP for the detection and differentiation of the canine piroplasm species and its use with filter paper-based technologies. Vet Parasitol 2007, 144:20-27.

12. Dawson JE, Stallknecht DE, Howerth EW, Warner C, Biggie K, Davidson WR, Lockhart JM, Nettles VF, Olson JG, Childs JE: Susceptibility of white-tailed deer (Odocoileus virginianus) to infection with Ehrlichia chaffeensis, the etiologic agent of human ehrlichiosis. J Clin Microbiol 1994, 32:2725-2728.

13. Petti CA: Detection and identification of microorganisms by gene amplification and sequencing. Clin Infect Dis 2007, 44:1108-1114.

14. Penzhorn BL, Kjemtrup AM, López-Rebollar LM, Conrad PA: Babesia leo n. sp. from lions in the Kruger National Park, South Africa, and its relation to other small piroplasms. J Parasitol 2001, 87:681-685.

15. Simking P, Wongnakphet S, Stich RW, Jittapalapong S: Detection of Babesia vogeli in stray cats of metropolitan Bangkok, Thailand. Vet Parasitol 2010, 173:70-75.

16. Taboada J, Lobetti R: Babesiosis. In Infectious Diseases of the Dog and Cat. Edited by Greene CE. Missouri: Saunders Elsevier; 2006:722-736.

17. Kelly PJ, Xu C, Lucas H, Loftis A, Abete J, Zeoli F, Stevens A, Jaegersen K, Ackerson K, Gessner A, Kaltenboeck B, Wang C: Ehrlichiosis, babesiosis, anaplasmosis and hepatozoonosis in dogs from St Kitts, West Indies. PLoS One 2013, 8:e53450.

18. Penzhorn BL: Babesiosis of wild carnivores and ungulates. Vet Parasitol 2006, 138:11-21.

19. Bosman AM, Oosthuizen MC, Peirce MA, Venter EH, Penzhorn BL: Babesia lengau sp. nov., a novel Babesia species in cheetah (Acinonyx jubatus, Schreber, 1775) populations in South Africa. J Clin Microbiol 2010, 48:2703-2708.

20. Bosman AM, Oosthuizen MC, Venter EH, Steyl JC, Gous TA, Penzhorn BL: Babesia lengau associated with cerebral and haemolytic babesiosis in two domestic cats. Parasit Vectors 2013, 6:128.

21. Giadinis ND, Chochlakis D, Kritsepi-Konstantinou M, Makridaki E, Tselentis Y, Kostopoulou D, Karatzias H, Psaroulaki A: Hemolytic disease in sheep attributed to a Babesia lengau-like organism. Vet Rec 2012, 170:155.

22. Pattullo KM, Wobeser G, Lockerbie BP, Burgess HJ: Babesia odocoilei infection in a Saskatchewan elk (Cervus elaphus canadensis) herd. $J$ Vet Diagn Invest 2013, 25:535-540.

23. Fritzen C, Mosites E, Applegate RD, Telford SR 3rd, Huang J, Yabsley MJ, Carpenter LR, Dunn JR, Moncayo AC: Environmental investigation following the first human case of babesiosis in Tennessee. J Parasitol 2014, 100:106-109.

24. Yabsley MJ, Murphy SM, Cunningham MW: Molecular detection and characterization of Cytauxzoon felis and a Babesia species in cougars from Florida. J Wildl Dis 2006, 42:366-374.

25. Inokuma H, Beppu T, Okuda M, Shimada Y, Sakata Y: Epidemiological survey of Anaplasma platys and Ehrlichia canis using ticks collected from dogs in Japan. Vet Parasitol 2003, 115:343-348.

26. Stewart CG, Hackett KJ, Collett MG: An unidentified Babesia of the domestic cat (Felis domesticus). J S Afr Vet Assoc 1980, 51:219-221. 
27. Shock BC, Moncayo A, Cohen S, Mitchell EA, Williamson PC, Lopez G, Garrison LE, Yabsley MJ: Diversity of piroplasms detected in blood-fed and questing ticks from several states in United States. Ticks Tick Borne Dis 2014, 5:373-380.

28. Meli ML, Cattori V, Martínez F, López G, Vargas A, Simón MA, Zorrilla I, Muñoz A, Palomares F, López-Bao JV, Pastor J, Tandon R, Willi B, HofmannLehmann R, Lutz H: Feline leukemia virus and other pathogens as important threats to the survival of the critically endangered Iberian lynx (Lynx pardinus). PLoS One 2009, 4:e4744.

29. André MR, Adania CH, Machado RZ, Allegretti SM, Felippe PA, Silva KF, Nakaghi AC, Dagnone AS: Molecular detection of Cytauxzoon spp. in asymptomatic Brazilian wild captive felids. J Wildl Dis 2009, 45:234-237.

30. Reichard MV, Van Den Bussche RA, Meinkoth JH, Hoover JP, Kocan AA: A new species of Cytauxzoon from Pallas' cats caught in Mongolia and comments on the systematics and taxonomy of piroplasmids. J Parasitol 2005, 91:420-426.

31. Foggin CA: A cytauxzoonosis-like disease in a cat in Zimbabwe. Zimbabwe Vet $J$ 1982, 13:28-30.

32. Joyner PH, Reichard MV, Meinkoth JH, Milne VE, Confer AW, Kocan AA, Hoover JP: Experimental infection of domestic cats (Felis domesticus) with Cytauxzoon manul from Pallas' cats (Otocolobus manu). Vet Parasitol 2007, 146:302-306.

33. Pawar RM, Poornachandar A, Srinivas P, Rao KR, Lakshmikantan U, Shivaji S: Molecular characterization of Hepatozoon spp. infection in endangered Indian wild felids and canids. Vet Parasitol 2012, 186:475-479.

34. Starkey LA, Panciera RJ, Paras K, Allen KE, Reiskind MH, Reichard MV, Johnson EM, Little SE: Genetic diversity of Hepatozoon spp. in coyotes from the south-central United States. J Parasitol 2013, 99:375-378.

35. East ML, Wibbelt G, Lieckfeldt D, Ludwig A, Goller K, Wilhelm K, Schares G, Thierer D, Hofer H: A Hepatozoon species genetically distinct from $H$. canis infecting spotted hyenas in the Serengeti ecosystem, Tanzania. J Wildl Dis 2008, 44:45-52.

36. ZinkI JG, McDonald SE, Kier AB, Cippa SJ, Small PJ: Cytauxzoon-like organisms in erythrocytes of two cheetahs. J Am Vet Med Assoc 1981, 179:1261-1262.

37. Liu J, Guan G, Liu Z, Liu A, Ma M, Bai Q, Yin H, Luo J: Additional data for a new Theileria sp. from China based on the sequences of ribosomal RNA internal transcribed spacers. Exp Parasitol 2013, 133:217-221.

38. Torina A, Naranjo V, Pennisi MG, Patania T, Vitale F, Laricchiuta P, Alongi A, Scimeca S, Kocan KM, de la Fuente J: Serologic and molecular characterization of tickborne pathogens in lions (Panthera leo) from the Fasano Safari Park, Italy. J Zoo Wildl Med 2007, 38:591-593.

39. Girard YA, Swift P, Chomel BB, Kasten RW, Fleer K, Foley JE, Torres SG, Johnson CK: Zoonotic vector-borne bacterial pathogens in California mountain lions (Puma concolor), 1987-2010. Vector Borne Zoonotic Dis 2012, 12:913-921.

40. Djiba ML, Mediannikov O, Mbengue M, Thiongane Y, Molez JF, Seck MT, Fenollar F, Raoult D, Ndiaye M: Survey of Anaplasmataceae bacteria in sheep from Senegal. Trop Anim Health Prod 2013, 45:1557-1561.

41. Inokuma H, Oyamada M, Kelly PJ, Jacobson LA, Fournier PE, Itamoto K, Okuda M, Brouqui P: Molecular detection of a new Anaplasma species closely related to Anaplasma phagocytophilum in canine blood from South Africa. J Clin Microbiol 2005, 43:2934-2937.

42. Adaszek L, Górna M, Skrzypczak M, Buczek K, Balicki I, Winiarczyk S: Three clinical cases of Anaplasma phagocytophilum infection in cats in Poland. J Feline Med Surg 2013, 15:333-337.

43. Heikkilä HM, Bondarenko A, Mihalkov A, Pfister K, Spillmann T: Anaplasma phagocytophilum infection in a domestic cat in Finland: case report. Acta Vet Scand 2010, 52:62.

44. Palomar AM, García-Álvarez L, Santibáñez S, Portillo A, Oteo JA: Detection of tick-borne 'Candidatus Neoehrlichia mikurensis' and Anaplasma phagocytophilum in Spain in 2013. Parasit Vectors 2014, 7:57.

45. Breitschwerdt EB, Hegarty BC, Qurollo BA, Saito TB, Maggi RG, Blanton LS, Bouyer DH: Intravascular persistence of Anaplasma platys, Ehrlichia chaffeensis, and Ehrlichia ewingii DNA in the blood of a dog and two family members. Parasit Vectors 2014, 1(7):298

46. Jahfari S, Coipan EC, Fonville M, van Leeuwen AD, Hengeveld P, Heylen D, Heyman P, van Maanen C, Butler CM, Földvári G, Szekeres S, van Duijvendijk G, Tack W, Rijks JM, van der Giessen J, Takken W, van Wieren SE, Takumi K, Sprong H: Circulation of four Anaplasma phagocytophilum ecotypes in Europe. Parasit Vectors 2014, 7:365.
47. Braga Mdo S, André MR, Freschi CR, Teixeira MC, Machado RZ: Molecular and serological detection of Ehrlichia spp. in cats on São Luís Island, Maranhão, Brazil. Rev Bras Parasitol Vet 2012, 21:37-41.

48. André MR, Dumler JS, Scorpio DG, Teixeira RH, Allegretti SM, Machado RZ: Molecular detection of tick-borne bacterial agents in Brazilian and exotic captive carnivores. Ticks Tick Borne Dis 2012, 3:247-253.

49. Filoni C, Catão-Dias JL, Cattori V, Willi B, Meli ML, Corrêa SH, Marques MC, Adania CH, Silva JC, Marvulo MF, Ferreira Neto JS, Durigon EL, de Carvalho VM, Coutinho SD, Lutz H, Hofmann-Lehmann R: Surveillance using serological and molecular methods for the detection of infectious agents in captive Brazilian neotropic and exotic felids. J Vet Diagn Invest 2012, 24:166-173.

50. Tateno M, Nishio T, Sakuma M, Nakanishi N, Izawa M, Asari Y, Okamura M, Maruyama S, Miyama TS, Setoguchi A, Endo Y: Molecular epidemiologic survey of Bartonella, Ehrlichia, and Anaplasma infections in Japanese Iriomote and Tsushima leopard cats. J Wildl Dis 2013, 49:646-652.

51. Matthewman LA, Kelly PJ, Wray K, Bryson NR, Rycroft AN, Raoult D, Mahan SM: Antibodies in cat sera from southern Africa react with antigens of Ehrlichia canis. Vet Rec 1996, 138:364-365.

doi:10.1186/s13071-014-0514-6

Cite this article as: Kelly et al:: Molecular detection of tick-borne pathogens in captive wild felids, Zimbabwe. Parasites \& Vectors 2014 7:514.

\section{Submit your next manuscript to BioMed Central and take full advantage of:}

- Convenient online submission

- Thorough peer review

- No space constraints or color figure charges

- Immediate publication on acceptance

- Inclusion in PubMed, CAS, Scopus and Google Scholar

- Research which is freely available for redistribution

Submit your manuscript at www.biomedcentral.com/submit
C Biomed Central 